\title{
The Utility of Economic Measures to Quantify the Burden of Tinnitus in Affected Individuals: A Scoping Review
}

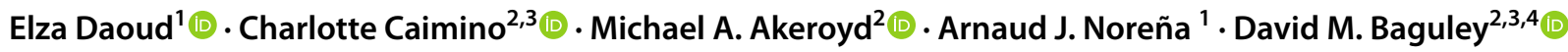

Accepted: 11 May 2021 / Published online: 2 July 2021

(c) The Author(s) 2021

\begin{abstract}
Background and objectives Tinnitus is a chronic subjective condition that impacts patients' health-related quality of life (HRQoL) and requires multidisciplinary interventions. In health economics, quality-adjusted life years (QALYs) and willingness to pay (WTP) are essential for evaluating treatment effectiveness in cost-effectiveness, cost-utility, or cost-benefit analysis. The extent to which these economic measures have been used in tinnitus research has not been investigated. The objectives of this scoping review were to explore findings and limitations of existing studies and provide an insight into how these economic measures could be used to quantify the burden of tinnitus in affected individuals.

Methods A scoping review was conducted following the Preferred Reporting Items for Systematic Reviews and Meta-Analyses (PRISMA) methodological framework. The search strategy involved four electronic databases. Records were included when QALYs or WTP were measured in individuals whose primary or secondary complaint was tinnitus.

Results A total of 15 studies were identified: three WTP assessment studies and 12 QALY assessment studies using direct preference-based measures (PBMs) $(n=4)$, indirect PBMs $(n=7)$, and a disease-specific psychometric instrument $(n=1)$. The limited use to date of PBMs to assess HRQoL in tinnitus patients is an important finding.

Conclusions Further studies using reliable economic methods and focusing on patients' WTP for treatment or their preference for their current health state are needed. Applying PBMs in tinnitus research is crucial not only for the healthcare decisionmaking process but also to improve patient-centred care.
\end{abstract}

Elza Daoud

elzadaoud@gmail.com

1 Centre National de la Recherche Scientifique, Aix-Marseille University, Marseille, France

2 Hearing Sciences, Mental Health and Clinical Neurosciences, School of Medicine, University of Nottingham, Nottingham, UK

3 National Institute for Health Research (NIHR) Nottingham Biomedical Research Centre, Nottingham, UK

4 Nottingham Audiology Services, Nottingham University Hospitals NHS Trust, Nottingham, UK

\section{Key Points for Decision Makers}

Despite the high economic and societal burden of tinnitus, there is as yet no evidence to set the threshold for the reimbursement of available treatments.

More multidisciplinary studies assessing quality-adjusted life years and the willingness to pay of patients are needed to shed light on the burden of this disease, the utility of present treatments, and the benefit of novel treatments as they are developed.

\section{Introduction}

In chronic diseases, patient-centred care aims to capture patients' perception and lived experience of the disease, associated handicap, treatment expectations, and adaptation 
mechanisms by assessing their health-related quality of life (HRQoL) [1, 2]. Its measurement is crucial for healthcare decision-making as it allows the quantification of the burden of the disease and the assessment of the benefits of an intervention from the patient's perspective [3].

Tinnitus, 'the conscious perception of an auditory sensation in the absence of a corresponding external stimulus' [4], is an auditory condition that can be chronically experienced by patients and can be associated with negative reactions $[5,6]$, resulting in depression, insomnia, anxiety or other comorbidities [7-10]. Each tinnitus patient presents with a unique clinical profile characterised by impairments in physical, psychological, social, and occupational functioning [9, 11-13]. Tinnitus prevalence varies eightfold between studies, probably due to the use of different definitions [14]. It has been observed that $2-4 \%$ of adults have been referred to a hospital due to their tinnitus, and $0.5-1 \%$ experienced limitations in their activities that impact HRQoL [15].

In the absence of a cure to alleviate tinnitus [16], patients are oriented toward various healthcare specialists [17, 18] and ongoing psychological and non-pharmacological approaches such as cognitive behavioural therapy (CBT) or tinnitus retraining therapy (TRT) [19], which require several sessions and engage recurring costs. Depending on tinnitus severity and the adopted clinical management strategy, annual costs of tinnitus care can be substantial: around US $\$ 660$ per patient in the United States [20], €1540 per patient in the Netherlands [21], and GB£720 per patient in the United Kingdom [22]. It is also important to note that there is no established regulatory pathway for tinnitus treatments and no precedent for pricing and reimbursement of medications [16].

A wide variety of outcome instruments are used to evaluate the therapeutic benefits of tinnitus treatment [23]. In publicly funded healthcare systems, costs and health outcomes appraisals are essential to enable comparability across all interventions, assess their value, and guide resource allocation decisions and prioritisation [24]. The use of disease-specific outcome measures complicates this process [25]. There is as yet no evidence to support the use of disease-specific psychometric instruments such as the Tinnitus Handicap Inventory (THI) [26], the Tinnitus Functional Index (TFI) [27], the Tinnitus Reaction Questionnaire (TRQ) [28], or the Tinnitus Primary Function Questionnaire (TPFQ) [6] to measure the impact of interventions for tinnitus on HRQoL in clinical trials [29-31].

Although there is no international agreement, most healthcare systems recommend using quality-adjusted life years (QALYs) to capture the health effects of an intervention in cost-effectiveness and cost-utility analyses [32]. QALYs result from using measures of HRQoL to adjust life years for quality and are defined on a cardinal scale from 0 ('dead' state) to 1 ('perfect-health' state) that measures each elapsed life year by the health state during this year. One QALY represents 1 year in perfect health [33]. QALYs can be estimated using direct and indirect approaches. Direct estimation is completed using either a 'choiceless' measure (i.e. participants are simply asked to state their values), such as the visual analogue scale (VAS), or preference-based measures (PBMs), which are choice-based measures, such as standard gamble (SG) and time trade-off (TTO) [34]. The magnitude of individual preference for each health state is expressed through decisions in a series of hypothetical scenarios involving risk, uncertainty, and trade-offs, which defines its 'utility' [35]. Indirect QALY valuation can be done using generic PBMs such as the EuroQol (EQ)-5D [36], the Short Form 6D (SF-6D)[37], and the Health Utilities Index (HUI) [38] or disease-specific PBMs. These multidimensional instruments take into account direct PBMs in their scoring algorithm: TTO for EQ-5D and SG for SF-6D and HUI $[39,40]$.

As an alternative measure, a patient's willingness to pay (WTP) for a QALY quantifies, in monetary value, the benefit of a specific health intervention and its effectiveness for cost-benefit analysis [41]. In other words, whereas QALY is used to assess patients' current health status, WTP is used to assess changes in health status provided by treatment. WTP can be evaluated via open- or close-ended questionnaires. Among the various approaches for estimating WTP, the most popular is contingent valuation. This method consists of providing individuals with a detailed description of a given improvement in health (in a hypothetical market) and asking them to state the maximum amount they would be willing to pay or the minimum amount they would be willing to accept in compensation for deprivation [42-44].

In a review to estimate the cost-effectiveness of tinnitus management in the UK, Stockdale et al. [22] indicated that there are no directly relevant studies allowing the estimation of QALYs associated with HRQoL improvement in tinnitus research. The primary objective of this study is to review studies that measured QALYs and WTP in tinnitus patients. A secondary aim is to identify research gaps and insight into how these economic measures could be useful in quantifying the burden of tinnitus in affected individuals. A scoping review was considered the most relevant methodology to describe evidence research gaps and achieve study aims $[45,46]$.

\section{Methods}

Throughout this scoping review, a six-step methodological framework was followed. This involved (1) setting the research question; (2) identifying studies using an in-depth literature search; (3) selecting relevant studies through screening; (4) extracting and charting of the data; (5) 
collating, summarising, and reporting the results; and (6) consulting with an expert clinician who did not take part in stages 1-5 [47].

\subsection{Identifying the Research Question}

This study was guided by the following research question: What is the extent of research with QALYs and WTP in tinnitus and the benefits and limitations of their use in quantifying the burden of tinnitus in affected individuals?

\subsection{Defining the Search Strategy and Study Selection}

Records for inclusion were identified from the results of electronic database searches. Search terms were tested and refined before conducting the final literature search by carrying out a limited search in the database MEDLINE to ensure relevant titles and abstracts were obtained. A search of the following electronic databases was implemented: MEDLINE, EMBASE, PsycINFO using the OvidSP platform, and Cumulative Index to Nursing and Allied Health Literature (CINAHL). Database searches were carried out in May 2020 using a specific search term strategy for each database (Table 1). Reference lists of included studies were manually searched to further identify relevant records for inclusion. No date limit was applied to ensure that all records of interest were obtained. All identified results were downloaded with citations, titles, and abstracts and imported into the reference manager Endnote X8.2. Articles were screened for duplicates, which were then removed.

\subsection{Eligibility Criteria}

Records were included if QALYs or WTP were used to quantify the burden of tinnitus in individuals whose primary or secondary complaint was current tinnitus. We searched for (1) indirect PBMs, i.e. one of the five groups of generic preference-based HRQoL instruments, namely Assessment of Quality of Life (AQoL), EQ-5D, HUI, Quality of WellBeing Scale (QWS), and SF-6D; (2) direct PBMs such as TTO and SG; (3) WTP studies; and (4) cost-effectiveness or cost-utility or cost-benefit analysis and health valuation and utility studies. Eligible records included randomised controlled trials (RCTs), cohort studies, and cross-sectional studies. Papers were included from all age groups and all countries, if available in English. Records were excluded when tinnitus and health state valuation measures were not reported.

\subsection{Inclusion Criteria}

Inclusion criteria were applied in two stages. In the first stage, titles and abstracts of included texts were screened independently using an iterative approach by two researchers $(\mathrm{ED}, \mathrm{CC})$. Articles were retained during phase one if the title and abstract included a reference to primary or secondary tinnitus and the health state valuation measures described above (or alluded to broader terminology, such as 'QALY' or 'utility' or 'WTP'). Full texts were retrieved for records

Table 1 Search term strategies for database searches

\begin{tabular}{lll}
\hline & MEDLINE, EMBASE and PsycINFO & CINAHL \\
\hline 1 & (economic OR economic analysis).ti,ab & Economic OR economic analysis \\
2 & (willingness to pay OR wtp OR cost benefit OR cost effectiveness & $\begin{array}{c}\text { Willingness to pay OR wtp OR cost benefit OR cost effectiveness OR } \\
\text { cost utility }\end{array}$ \\
& OR cost utility).ti,ab & Time trade off OR tto OR standard gamble OR sg \\
3 & (time trade off OR tto OR standard gamble OR sg).ti,ab & QALY OR quality adjusted life years OR health valuation OR health \\
4 & (QALY OR quality adjusted life years OR health valuation OR & utilit* \\
& health utilit*).ti,ab & EuroQ*OR EQ 5D OR EQ 5D* OR EQ? 5D \\
5 & (EuroQ*OR EQ 5D OR EQ 5D* OR EQ? 5D).ti,ab & HUI OR Health Utilities Index \\
6 & (HUI OR Health Utilities Index).ti,ab & Quality of Wellbeing OR Quality of Well-Being OR QWB OR \\
7 & (Quality of Wellbeing OR Quality of Well-Being OR QWB OR & QWB-SA \\
& QWB-SA).ti,ab & AQoL OR assessment of quality of life \\
8 & (AQoL OR assessment of quality of life).ti,ab & (SF-6D OR SF6D).ti,ab \\
9 & (SF-6D OR SF6D).ti,ab & 15D OR 16D OR 17D OR 15 dimensional OR 16 dimensional OR 17 \\
10 & (15D OR 16D OR 17D OR 15 dimensional OR 16 dimensional OR & dimensional \\
& 17 dimensional).ti,ab & 1 OR 2 OR 3 OR 4 OR 5 OR 6 OR 7 OR 8 OR 9 OR 10 \\
11 & 1 OR 2 OR 3 OR 4 OR 5 OR 6 OR 7 OR 8 OR 9 OR 10 & tinnitus \\
12 & tinnitus & 11 AND 12 \\
13 & 11 AND 12 &
\end{tabular}

CINAHL Cumulative Index to Nursing and Allied Health Literature 
that the researchers agreed were eligible for full-text screening in the second stage. The screening was performed independently by two researchers (ED, CC) and involved the hierarchical application of exclusion criteria. First, articles were excluded if study participants did not have tinnitus. Second, records were excluded if the health state valuation measures described above were not used. If there was a disagreement between researchers regarding the inclusion of records in this review, a third researcher (DB) was consulted to arbitrate.

\subsection{Data Extraction}

Data were extracted independently by two researchers (ED, $\mathrm{CC}$ ) for each record. The following items were included in data extraction: name of the authors, year of publication, the title of the study, country, study design, study population, age of participants, sample size, number of participants with tinnitus, tinnitus type, study aim, the method selected for QALY or WTP measurement, justification of method selection, psychometric evidence of selected instruments (correlation with a disease-specific questionnaire used to assess tinnitus severity), authors' concerns regarding the use of tools, mean health state values specific to tinnitus, and any notes (or limitation) of included records. Any disagreements in data extraction were reviewed, and a final data set was decided.

\section{Results}

A total of 245 individual results were identified from the database search. Title and abstract screening resulted in the exclusion of 222 records. After reviewing the full text of the remaining records, 15 were included (see Fig. 1). Their details are summarised below in the 'Study Characteristics' subsection. The subsections report the studies of relevance to the primary question ('Main Findings') and the secondary questions ('Research Gaps').
Fig. 1 PRISMA flow chart of the study selection process. CINAHL Cumulative Index to Nursing and Allied Health Literature, PRISMA Preferred Reporting Items for Systematic Reviews and Meta-Analyses, $Q A L Y$ quality-adjusted life year, $W T P$ willingness to pay

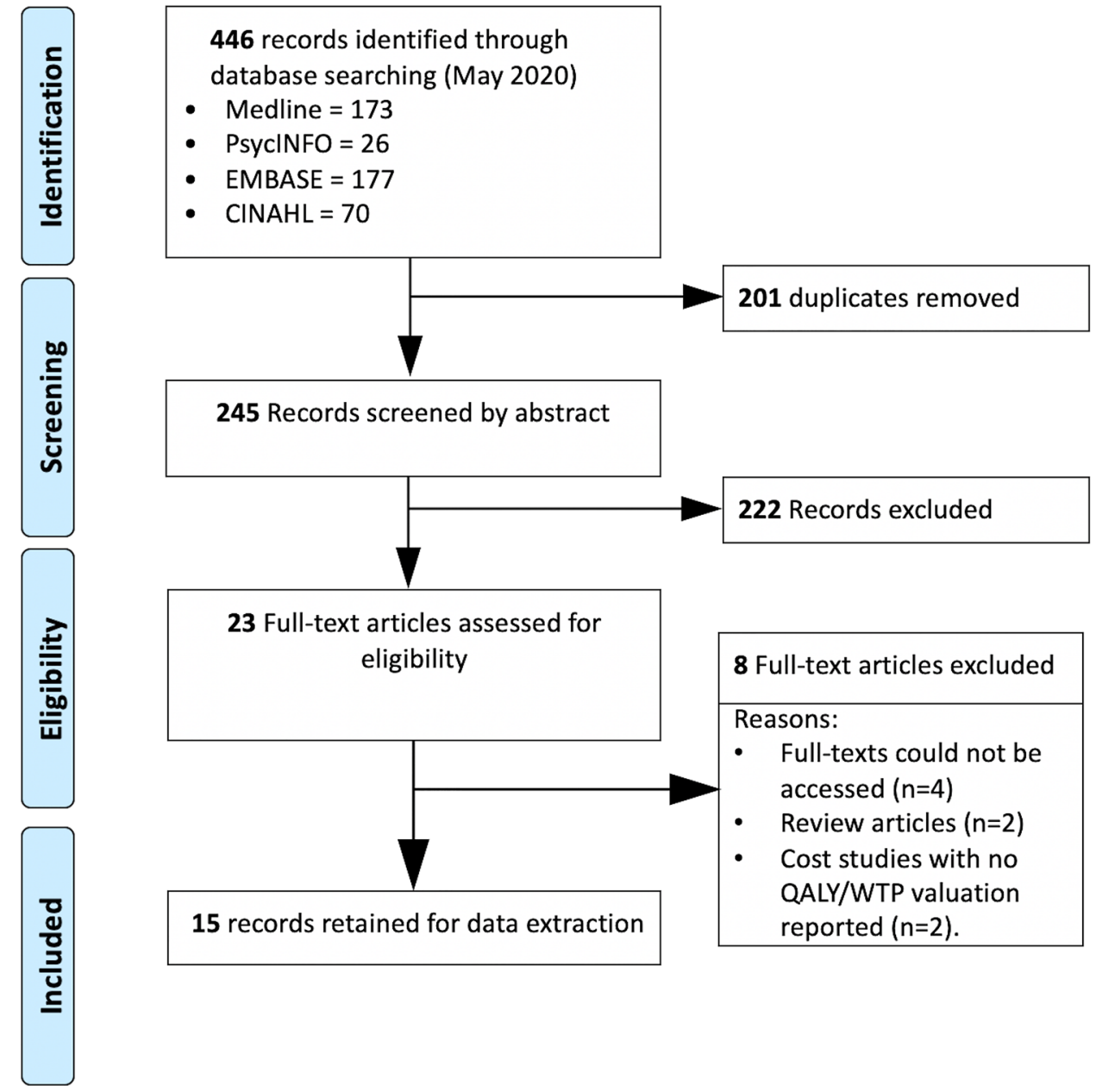


Table 2 Demographics and characteristics of included articles

\begin{tabular}{|c|c|c|c|c|c|c|c|c|}
\hline References \# & Authors & Date & Country & Measure & Study design & $\begin{array}{l}\text { Type of tinnitus } \\
\text { complaint }\end{array}$ & $\begin{array}{l}\text { Age in years: } \\
\text { Mean (SD) } \\
\text { Range }\end{array}$ & Sample size \\
\hline [61] & Engineer et al. & 2013 & USA & WTP & Cross-sectional & Non-specified & $\begin{array}{l}47.4 \\
25-65\end{array}$ & 439 \\
\hline [62] & Tyler & 2012 & USA & WTP & Cross-sectional & Non-specified & $\begin{array}{l}66.4 \\
31-90\end{array}$ & 197 \\
\hline [63] & Smit et al. & 2018 & The Netherlands & WTP & Cross-sectional & Non-specified & $\begin{array}{l}58(12) \\
18-64\end{array}$ & 415 \\
\hline [48] & $\begin{array}{l}\text { Happich and } \\
\text { Mazurek }\end{array}$ & 2002 & Germany & QALYs & Cross-sectional & Non-specified & $\begin{array}{l}54 \\
16-85\end{array}$ & 420 \\
\hline [49] & $\begin{array}{l}\text { Happich and Mue- } \\
\text { hlbacher }\end{array}$ & 2003 & & & & & & \\
\hline [50] & $\begin{array}{l}\text { Happich and von } \\
\text { Lengerke }\end{array}$ & 2005 & & & & & & \\
\hline [51] & Happich et al. & 2009 & & & & & & \\
\hline [52] & Cima et al. & 2012 & The Netherlands & QALYs & Randomised con- & Tinnitus with sub- & $54.19(11.54)$ & 428 \\
\hline [53] & Maes et al. & 2011 & & & trolled trial & jective complaints & $20-85$ & \\
\hline [54] & Maes et al. & 2014 & & & & & & \\
\hline [59] & $\begin{array}{l}\text { Newman and San- } \\
\text { dridge }\end{array}$ & 2012 & USA & QALYs & $\begin{array}{l}\text { Retrospective } \\
\text { between-subject } \\
\text { clinical design }\end{array}$ & $\begin{array}{l}\text { Tinnitus with sub- } \\
\text { jective complaints }\end{array}$ & $\begin{array}{l}53.5 \\
29-77\end{array}$ & 56 \\
\hline [58] & Summerfield et al. & 2019 & UK & QALYs & $\begin{array}{l}\text { Prospective, longi- } \\
\text { tudinal study }\end{array}$ & $\begin{array}{l}\text { Tinnitus associ- } \\
\text { ated with hearing } \\
\text { impairments }\end{array}$ & $\begin{array}{l}50.7 \\
18.0-79.3\end{array}$ & 147 \\
\hline [57] & Stephens et al. & 2012 & Finland & QALYs & Cross-sectional & $\begin{array}{l}\text { Tinnitus associated } \\
\text { with Menière's } \\
\text { disease }\end{array}$ & $\begin{array}{l}63 \\
26-88\end{array}$ & 183 \\
\hline [55] & Robinson et al. & 2005 & USA & QALYs & $\begin{array}{l}\text { Randomised con- } \\
\text { trolled trial }\end{array}$ & Non-specified & 57 & 115 \\
\hline [56] & Robinson et al. & 2008 & USA & QALYs & $\begin{array}{l}\text { Randomised con- } \\
\text { trolled trial }\end{array}$ & Non-specified & $\begin{array}{l}55(11.28) \\
35-77\end{array}$ & 65 \\
\hline
\end{tabular}

$Q A L Y$ quality-adjusted life year, $W T P$ willingness to pay

\subsection{Studies Characteristics}

The studies were categorised as WTP assessment $(n=3)$ and QALY assessments using direct PBMs [48-51] $(n=$ $4)$, indirect PBMs [52-58] $(n=7)$, and disease-specific psychometric instrument [59] $(n=1)$. The characteristics and demographics of these studies are detailed in Table 2. We made two decisions to link studies. First, the study by Maes et al. [53] was performed on the same study population recruited for the RCT [52] and was followed by costeffectiveness analysis [54]. Based on this disclosure made by the authors themselves, it was decided to merge the evidence reported in these studies. Second, after comparing author names, location and setting, numbers of participants and baseline data, date and duration of the study [60], it was decided to link together complementary findings from multiple reports [49-51] of the first cross-sectional study from Happich and Mazurek [48].

\subsection{Main Findings}

\subsubsection{Methods Used for Health State Valuation}

In available studies [61-63], participants' WTP for treatment was assessed via close-ended questionnaires. In two studies [61, 62], choices given to participants' comprised the following WTP categories: US $\$ 1000$, US $\$ 5000$, US\$10,000, US\$25,000, and US\$50,000. In Smit et al. [63], the options to be considered were listed as a proportion of the participant's monthly income and ranged from less than one fourth to more than 20 times.

Various generic preference-based HRQoL instruments were used to calculate QALYs: HUI2 $(n=1)$ [58], HUI3 $(n=2)[53,58]$, EQ-5D $(n=3)$ [53, 57, 58], SF-6D [58] $(n=1)$, and QWS $(n=2)[55,56]$. Another study [59] calculated the cost of treatment per QALY using the THI based on a specific formula [64]: QALYs were estimated by multiplying the life expectancy (the difference between 
chronological age and projected life expectancy [65]) with the difference score (pre- and post-fitting) on the THI. Direct non-PBMs (VAS) and PBMs (SG, TTO) were also used [48]. The use of AQoL instruments has not been considered in tinnitus research.

\subsubsection{WTP and Mean Health State Values}

Both studies [61, 62] show the most selected WTP category to reduce tinnitus by half was US $\$ 1000$ for all respondents, and the most chosen WTP category to eliminate it was US $\$ 5000$. Engineer et al. [61] show that $63.2 \%$ of the 'very loud' subgroup would pay more than US $\$ 10,000$ to eliminate tinnitus, and $26.7 \%$ of those are willing to pay US $\$ 50,000$. However, in both studies, patients' financial status, which directly influences their WTP, was not measured [62]. Smit et al. [63] found that $58 \%$ of participants would be willing to pay more than their total monthly income to cure tinnitus. Of the participants with a slightly lower age range, $25 \%$ reporting a significantly higher tinnitus loudness, burden, and associated psychological distress would be willing to pay 20 times their monthly income for a cure.

For QALY assessment, three studies reported at least one mean health state valuation for tinnitus alone. Two studies reported mean utility scores using QWB, respectively, for two different samples of the same study at baseline $[55,56]$. Another study [53] showed lower utility scores with HUI3 (0.63) than with EQ-5D (0.77) at baseline. Although, in general, the TTO (used for the EQ-5D) leads to lower scores than the SG (used for the HUI3) [66], authors explained that while the utility scoring function of the EQ-5D is additive, assuming no interaction for preferences among attributes at all, the HUI3 uses a multiplicative scoring function, with the effect on the index of a change in the level of one attribute depending on the levels of other attributes. The utility scores of the HUI3 were expected to be lower because they take into account the effect of comorbidity. In general, low utility scores found at baseline (before interventions) indicate that tinnitus is a relatively high burden to affected patients. One study [48] using direct measures to value QALYs found that patients, in general, assign higher utilities to their condition than unaffected people asked to rate this condition. This difference in QALYs was more pronounced for VAS ( $0.53 \mathrm{vs}$ $0.34)$ than for SG (0.88 vs 0.80$)$ and TTO (0.83 vs 0.78$)$. The authors explained that, on average, disease sufferers are less willing to take risks than unaffected persons. They also stated that formulating an accurate description of a tinnitus patient's subjective experience that the general public can adequately understand is challenging.

\subsection{Research Gaps}

\subsubsection{Appropriateness of Elicitation Methods}

Studies reported WTP estimates per subgroup based on the patient's evaluation of tinnitus loudness and associated annoyance on a VAS [62] or a Likert scale question [61]. One study [62] found a significantly low correlation between WTP to eliminate tinnitus and tinnitus loudness $(r=0.263$, $p<0.001)$ and annoyance $(r=0.284, p<0.001)$. However, the authors of both studies cautioned on the interpretation of WTP valuations because open-ended questionnaires were not provided, and the given category choices could influence the responses.

For QALY indirect assessment, two studies examined aspects of validity and feasibility of generic PBMs for tinnitus. Maes et al. [53] compared HUI3 and the three-level version of EQ-5D (EQ-5D-3L) and concluded that although both utility measures discriminate between clinically different groups, the ceiling effects were more frequent in the EQ-5D health state descriptions. The HUI3 also shows a significant effect on the hearing and cognition dimensions. The authors also examined whether a change in mean utility scores with the HUI3 or EQ-5D was accompanied by a change in a tinnitus psychometric questionnaire [the Tinnitus Questionnaire (TQ)] [53] and concluded that the HUI3 was slightly more responsive than the EQ-5D. Besides, one study [58] confirmed that EQ-5D-3L was more sensitive to the slight improvement in tinnitus discomfort (measured with a Likert-based questionnaire) after cochlear implantation. The authors suggested that the decision to use HUI3 or EQ-5D depends on policymakers' preferences in different jurisdictions. They also commented that SF-6D was insensitive to change in tinnitus and hearing impairment. In Stephens et al. [57], EQ-5D did not capture the perceived consequences of tinnitus in the HRQoL of patients with Menière's disease. In Robinson et al. [55], tinnitus severity was measured explicitly using a psychometric questionnaire (Tinnitus Handicap Questionnaire [THQ]), and the authors concluded that the QWS was insensitive to changes in tinnitus. Robinson et al. [56] found that while tinnitus-related aspects of HRQoL (measured with the TRQ) and depression [measured with the Beck Depression Inventory (BDI)] were improved with treatment, the QWS score did not change.

\subsubsection{Justifications for Instrument and Respondent Selection}

In Engineer et al. [61], the justification for using a closedended questionnaire to assess patients' WTP was based on pilot studies indicating that open-ended formats were more challenging to perform. However, authors [61] suggested that other forms of questions with increased uncertainties 
or prompting respondents to consider the potential risks of treatments could influence their responses. Besides, there was no justification for setting the lowest cut-off category at US\$1000 in either study. For QALY assessment using direct PBMs [48-51] and indirect PBMs [52-58], the authors gave a general overview of the methods used without stating any tinnitus-specific justification. One study [53] provided a tinnitus-specific explanation commenting that the hearing and cognition dimensions in HUI3 are likely to be relevant for tinnitus patients. Resulting RCT [52] and cost-effectiveness analysis [54] studies using HUI3 cited the results drawn from [53], which found adequate responsiveness associated with this index in the tinnitus population. The justification provided by Newman and Sandridge [59] for the use of the THI to calculate QALYs was that the THI meets the requirements as an appropriate outcome measure for economic analyses [67] because of 'its capacity to assess changes in HRQoL associated with tinnitus.' However, the THI is criticised for lacking sensitivity to change [31, 68]. The authors were concerned that the results were obtained from the selected samples (tinnitus self-help group [62], members of a society of tinnitus patients [63], street sample [48]) and therefore could not be extrapolated to the general tinnitus population. The main findings and the research gaps discussed above are summarised in Table 3.

\section{Discussion}

Compared to other chronic diseases [70, 71], the lack of economic evaluation studies in tinnitus research is an essential finding of this scoping review. The variations in WTP and mean health state values between studies make it difficult to draw definitive conclusions and calculate WTP per QALY. QALYs and WTP valuation studies are necessary for resource allocation purposes. A consistent design, including a justification of the elicitation method used, reporting of respondents' characteristics, and framing of questions and response options, is crucial to allow the generalisability of the results. First, we discuss the findings and limitations of available studies on QALY and WTP and new directions for future research. Second, we discuss the utility of these economic measures in quantifying the burden of tinnitus in affected individuals.

Although it is impossible to draw any general conclusion from the three WTP studies, available data showed that patients with severe tinnitus would be willing to pay around an average annual salary in their countries [61, 63]. Compared to the costs $[17,18]$, these amounts are relatively high, indicating a potential economic benefit in finding a tinnitus treatment. Concerning the limitations, the fact that the majority of patients have paid less than US\$500 in the past [45] makes the minimal category of payment scale set at US\$1000 questionable [57, 59]. As the choice of WTP categories in close-ended questionnaires could influence the respondent's response, open-ended questionnaires asking respondents to give a range of WTP instead of a specific amount could reduce the risk of bias [72]. WTP valuation is influenced by socio-demographic factors, including the nature of the healthcare system (private/public) or income [69], which should be considered. The use of generic PBMs (EQ-5D, HUI3, SF-6D, and QWS) was limited to four studies. The SF-6D was found to be insensitive to tinnitus changes in one study. However, the SF-36, from which the SF-6D was derived, has been extensively used in tinnitus research and was able to capture changes in tinnitus severity $[15,73,74]$. More research is needed to conclude on its performance in the tinnitus population. In contrast to domains included in other generic preference-based instruments such as EQ-5D (Mobility, Self-Care, Usual Activities, Pain/Discomfort, Anxiety/ Depression) and SF-6D (Physical Functioning, Role Limitations, Social Functioning, Pain, Mental Health, Vitality), the HUI2/3 systems (Vision, Hearing, Speech, Ambulation, Dexterity, Emotion, Cognition, Pain) are based on measures reflecting functional capacity instead of performance [75]. In theory, the HUI3, which is the only instrument covering speech and cognition, may allow a more appropriate description of the tinnitus population. In some jurisdictions, guidelines recommend the use of EQ-5D unless the latter is proven inappropriate. Comparing the HUI and the EQ-5D using the THI, could provide an answer. If generic PBM instruments are not sufficiently sensitive to evaluate tinnitus-related QALYs, a disease-specific preference-based questionnaire may be used as an alternative [32]. A disease-specific preference-based questionnaire for tinnitus does not exist and could be developed by mapping the items of a disease-specific instrument (THI or TFI) onto the utility algorithm of a generic instrument such as the EQ-5D [76, 77]. This procedure has already been done in vision research $[78,79]$. Evaluating HRQoL using PBMs in clinical trials can provide insight into treatment effectiveness and advantages even before performing cost-effectiveness analysis, reduce sample size during economic analysis, or facilitate a subsequent cost-utility analysis following an RCT [80, 81].

Recognizing what affected aspects of HRQoL matter more to patients would help clinicians and researchers understand their treatment preferences and subsequent satisfaction and adherence [82]. Psychometric instruments, which are currently used to measure tinnitus burden, equally weigh HRQoL domains without considering their relative significance, interactions, and contribution to the burden of the disease from the patients' perspective. In comparing two treatments, each might perform better against one dimension, making it harder to determine which treatment was more effective [83]. PBMs mainly aim to capture patients' 


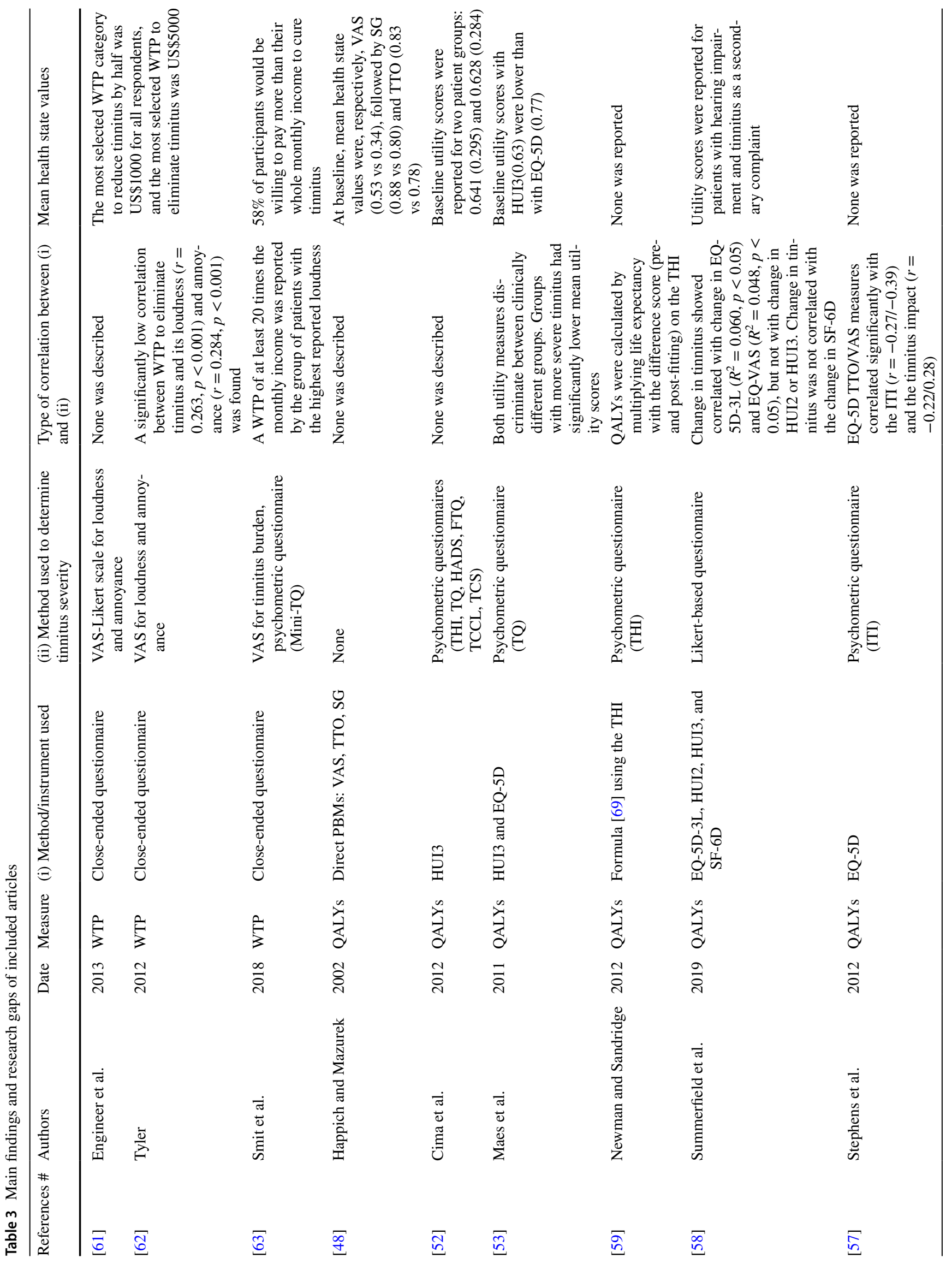




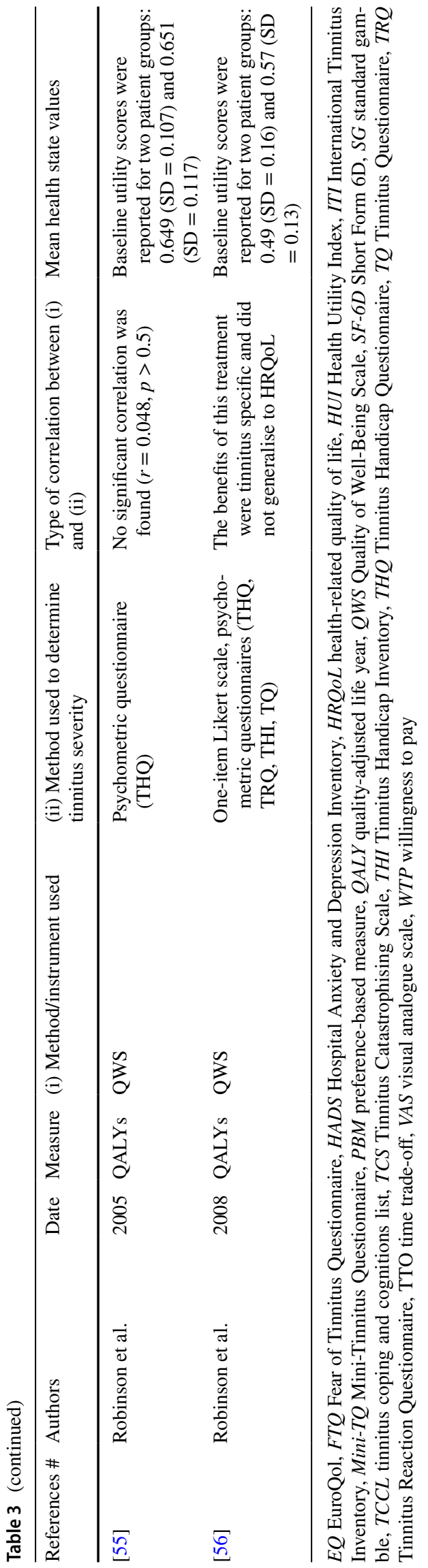

preferences and treatment expectations and might be used in clinical research to provide information on the degree to which tinnitus affects a patient (using TTO or SG) and estimating the potential value that a given treatment may provide (using WTP). Understanding the burden can also be done by comparing tinnitus with other chronic diseases. For example, the pathophysiological similitudes between chronic pain and tinnitus have been highlighted in the literature [84-86]. Comparing TTO and SG of tinnitus and chronic pain or WTP for tinnitus and chronic pain treatments may shed light on similarities in their impact on HRQoL. Besides, as patients' attitude toward risk is involved in direct QALY valuation [35] and might be influenced by their traits and treatment expectations [87], one hypothesis to test, using direct QALY valuation methods, is whether higher tinnitus severity leads to more risk-averse behaviour toward trying new therapies. Finally, individuals' demographic (cultural) and socioeconomic characteristics influence QALY valuation [88] and provide some direction concerning how the burden of hearing-related diseases, including tinnitus, could be differently perceived in different cultures (depending on these environmental factors).

A limitation of this review is the possibility that the search strategy could have overlooked relevant articles. Systematic searching can be challenging in studies involving the measurement of HRQoL outcomes, considering the absence of formal indexing standards in databases and the authors' inconsistent reporting style. Only documents in English were included. Some studies that used health state valuation methods written in other languages might have been missed.

\section{Conclusion}

This study highlights the limited use of economic measures in tinnitus research and the methodological shortcomings of available studies. There is no evidence to support the calculation of WTP per QALY for a tinnitus treatment, which presently impedes the resource allocation process. More studies estimating the correlation between generic PBMs and psychometric treatments and establishing head-to-head comparisons of generic PBMs are urgently required to assess which of these is more sensitive to distinguish tinnitus sufferers according to the severity of their symptoms and which dimensions/attributes of the generic PBMs underpin sensitivity to tinnitus and to treatments that alleviate it.

Acknowledgements We gratefully thank the reviewers for their valuable comments and feedbacks. 


\section{Declarations}

Funding This project has received funding from the European Research Council (ERC) under the European Union's Horizon 2020 research and innovation programme (grant agreement $n^{\circ} 764604$ ). The funder had no role in study design, data collection and analysis, decision to publish, or manuscript preparation. David M. Baguley and Charlotte Caimino are supported by the National Institute for Health Research (NIHR), but the views herein are their own and do not represent those of the NIHR nor the UK Department of Health and Social Care. Michael Akeroyd is supported by the Medical Research Council (Grant number MR/S002898/1).

Conflict of interest/Competing interests The authors declared no potential conflicts of interest with respect to the research, authorship, and/or publication of this article.

Availability of data and material The data and material of this systematic review are available to the public upon request.

Code availability Not applicable.

Authors' contributions ED and DB conceived the presented idea. ED and $\mathrm{CC}$ conducted the assessments of the titles, abstracts, and full texts independently. ED, CC, and DB discussed study selection and study details and decided which studies were to be included in the review. ED wrote the manuscript with input from all authors. All authors aided in interpreting the results and revised the manuscript.

Open Access This article is licensed under a Creative Commons Attribution-NonCommercial 4.0 International License, which permits any non-commercial use, sharing, adaptation, distribution and reproduction in any medium or format, as long as you give appropriate credit to the original author(s) and the source, provide a link to the Creative Commons licence, and indicate if changes were made. The images or other third party material in this article are included in the article's Creative Commons licence, unless indicated otherwise in a credit line to the material. If material is not included in the article's Creative Commons licence and your intended use is not permitted by statutory regulation or exceeds the permitted use, you will need to obtain permission directly from the copyright holder. To view a copy of this licence, visit http://creativecommons.org/licenses/by-nc/4.0/.

\section{References}

1. Brousse C, Boisaubert B. La qualité de vie et ses mesures. Rev Med Interne. 2007;28(7):458-62. https://doi.org/10.1016/j. revmed.2007.02.010.

2. Tyler R, Perreauf A, Mohr A-M, Ji H, Mancini PC. An exploratory step toward measuring the "meaning of life" in patients with tinnitus and in cochlear implant users. J Am Acad Audiol. 2020;31(4):277-85. https://doi.org/10.3766/jaaa.19022.

3. Brazier J, Ratcliffe J. Measurement and valuation of health for economic evaluation. In: Quah SR, editor. International encyclopedia of public health. 2nd ed. Oxford: Academic Press; 2017. p. 586-93. https://doi.org/10.1016/B978-0-12-803678-5.00457-4.

4. Baguley D, McFerran D, Hall D. Tinnitus. Lancet (London, England). 2013;382(9904):1600-7. https://doi.org/10.1016/S01406736(13)60142-7.

5. Tyler RS, Aran JM, Dauman R. Recent advances in tinnitus. Am J Audiol. 1992;1(4):36-44. https://doi.org/10.1044/1059-0889. 0104.36.
6. Tyler R, Ji H, Perreau A, Witt S, Noble W, Coelho C. Development and validation of the tinnitus primary function Questionnaire. Am J Audiol. 2014;23(3):260-72. https://doi.org/10.1044/ 2014 AJA-13-0014.

7. Tyler RS, Baker LJ. Difficulties experienced by tinnitus sufferers. J Speech Hear Disord. 1983;48(2):150-4. https://doi.org/10.1044/ jshd.4802.150.

8. Crönlein T, Langguth B, Pregler M, Kreuzer PM, Wetter TC, Schecklmann M. Insomnia in patients with chronic tinnitus: cognitive and emotional distress as moderator variables. J Psychosom Res. 2016;83:65-8. https://doi.org/10.1016/j.jpsychores.2016.03. 001.

9. Tegg-Quinn S, Bennett RJ, Eikelboom RH, Baguley DM. The impact of tinnitus upon cognition in adults: a systematic review. Int J Audiol. 2016;55(10):533-40. https://doi.org/10.1080/14992 027.2016 .1185168 .

10. Lasisi AO, Gureje O. Prevalence of insomnia and impact on quality of life among community elderly subjects with tinnitus. Ann Otol Rhinol Laryngol. 2011;120(4):226-30. https://doi.org/10. 1177/000348941112000402.

11. Fetoni AR, Lucidi D, Corso ED, Fiorita A, Conti G, Paludetti G. Relationship between Subjective Tinnitus Perception and Psychiatric Discomfort. Int Tinnitus J. 2017;20(2):76-82. https:// doi.org/10.5935/0946-5448.20160015.

12. Weidt S, Delsignore A, Meyer M, Rufer M, Peter N, Drabe N, Kleinjung T. Which tinnitus-related characteristics affect current health-related quality of life and depression? A cross-sectional cohort study. Psychiatry Res. 2016;237:114-21. https:// doi.org/10.1016/j.psychres.2016.01.065.

13. Zeman F, Koller M, Langguth B, Landgrebe M. Which tinnitusrelated aspects are relevant for quality of life and depression: results from a large international multicentre sample. Health Qual Life Outcomes. 2014;12:7. https://doi.org/10.1186/ 1477-7525-12-7.

14. McCormack A, Edmondson-Jones M, Somerset S, Hall D. A systematic review of the reporting of tinnitus prevalence and severity. Hear Res. 2016;337:70-9. https://doi.org/10.1016/j. heares.2016.05.009.

15. Adrian D, El Refaie A. The epidemiology of tinnitus. In: Tyler $\mathrm{R}$, editor. The handbook of tinnitus. Norwich: Singular; 2000. p. 1-23.

16. McFerran DJ, Stockdale D, Holme R, Large CH, Baguley DM. Why is there no cure for tinnitus? Front Neurosci. 2019. https:// doi.org/10.3389/fnins.2019.00802.

17. Cima RFF, Kikidis D, Mazurek B, Haider HF, Cederroth CR, Noreña AJ, et al. Tinnitus healthcare: a survey revealing extensive variation in opinion and practices across Europe. BMJ Open. 2020. https://doi.org/10.1136/bmjopen-2019-029346.

18. Kreuzer PM, Vielsmeier V, Langguth B. Chronic tinnitus: an interdisciplinary challenge. Deutsches Arzteblatt International. 2013;110(16):278-84. https://doi.org/10.3238/arztebl.2013. 0278.

19. Fuller T, Cima R, Langguth B, Mazurek B, Vlaeyen JW, Hoare DJ. Cognitive behavioural therapy for tinnitus. Cochrane Database Syst Rev. 2020;1:CD012614. https://doi.org/10.1002/14651858. CD012614.pub2.

20. Goldstein E, Ho C-X, Hanna R, Elinger C, Yaremchuk KL, Seidman MD, Jesse MT. Cost of care for subjective tinnitus in relation to patient satisfaction. Otolaryngol Head Neck Surg. 2015;152(3):518-23. https://doi.org/10.1177/0194599814566179.

21. Maes IHL, Cima RFF, Vlaeyen JW, Anteunis LJC, Joore MA. Tinnitus: a cost study. Ear Hear. 2013;34(4):508-14. https://doi. org/10.1097/AUD.0b013e31827d113a.

22. Stockdale D, McFerran D, Brazier P, Pritchard C, Kay T, Dowrick C, Hoare DJ. An economic evaluation of the healthcare 
cost of tinnitus management in the UK. BMC Health Serv Res. 2017;17(1):577. https://doi.org/10.1186/s12913-017-2527-2.

23. Hall DA, Haider H, Szczepek AJ, Lau P, Rabau S, Jones-Diette $\mathrm{J}$, et al. Systematic review of outcome domains and instruments used in clinical trials of tinnitus treatments in adults. Trials. 2016;17(1):270. https://doi.org/10.1186/s13063-016-1399-9.

24. Brazier J, Tsuchiya A. Improving cross-sector comparisons: going beyond the health-related QALY. Appl Health Econ Health Policy. 2015;13(6):557-65. https://doi.org/10.1007/s40258-015-0194-1.

25. Sanders GD, Neumann PJ, Basu A, Brock DW, Feeny D, Krahn $\mathrm{M}$, et al. Recommendations for conduct, methodological practices, and reporting of cost-effectiveness analyses: second panel on costeffectiveness in health and medicine. JAMA. 2016;316(10):1093103. https://doi.org/10.1001/jama.2016.12195.

26. Newman CW, Jacobson GP, Spitzer JB. Development of the Tinnitus Handicap Inventory. Arch Otolaryngol Head Neck Surg. 1996;122(2):143-8. https://doi.org/10.1001/archotol.1996.01890 140029007.

27. Meikle MB, Henry JA, Griest SE, Stewart BJ, Abrams HB, McArdle R, et al. The Tinnitus Functional Index: development of a new clinical measure for chronic, intrusive tinnitus. Ear Hear. 2012;33(2):153-76. https://doi.org/10.1097/AUD.0b013e3182 $2 \mathrm{f} 67 \mathrm{c} 0$.

28. Wilson PH, Jane H, Maitland B, George H. Tinnitus reaction questionnaire. J Speech Lang Hear Res. 1991;34(1):197-201. https:// doi.org/10.1044/jshr.3401.197.

29. Fackrell K, Hall DA, Barry JG, Hoare DJ. Psychometric properties of the Tinnitus Functional Index (TFI): assessment in a UK research volunteer population. Hear Res. 2016;335:220-35. https://doi.org/10.1016/j.heares.2015.09.009.

30. Kamalski DM, Hoekstra CE, van Zanten BG, Grolman W, Rovers MM. Measuring disease-specific health-related quality of life to evaluate treatment outcomes in tinnitus patients: a systematic review. Otolaryngol Head Neck Surg. 2010;143(2):181-5. https:// doi.org/10.1016/j.otohns.2010.03.026.

31. Tyler RS, Oleson J, Noble W, Coelho C, Ji H. Clinical trials for tinnitus: study populations, designs, measurement variables, and data analysis. In: Langguth B, Hajak G, Kleinjung T, Cacace A, Møller AR, editors. Progress in brain research, vol. 166. Amsterdam: Elsevier; 2007. p. 499-509. https://doi.org/10.1016/S00796123(07)66048-8.

32. Rowen D, Azzabi Zouraq I, Chevrou-Severac H, van Hout B. International regulations and recommendations for utility data for health technology assessment. Pharmacoeconomics. 2017;35(1):11-9. https://doi.org/10.1007/s40273-017-0544-y.

33. Thomas R, Chalkidou K. Cost-effectiveness analysis. Health system efficiency: how to make measurement matter for policy and management [Internet]. European Observatory on Health Systems and Policies. 2016. http://www.ncbi.nlm.nih.gov/books/NBK43 6886/. Accessed May 2020

34. Salomon JA. Quality adjusted life years. In: Quah SR, editor. International encyclopedia of public health. 2nd ed. Oxford: Academic Press; 2017. p. 224-8. https://doi.org/10.1016/B9780-12-803678-5.00368-4.

35. Neumann PJ, Goldie SJ, Weinstein MC. Preference-based measures in economic evaluation in health care. Annu Rev Public Health. 2000;21:587-611. https://doi.org/10.1146/annurev.publh ealth.21.1.587.

36. Brooks R, Rabin R, de Charro F, editors. The measurement and valuation of health status using EQ-5D: a European Perspective: evidence from the EuroQol BIOMED Research Programme. Dordrecht: Springer; 2003. https://doi.org/10.1007/ 978-94-017-0233-1.

37. Ware J, Kosinski M, Gandek B. SF-36 health survey: manual \& interpretation guide. Lincoln: QualityMetric Incorporated; 1993.
38. Horsman J, Furlong W, Feeny D, Torrance G. The Health Utilities Index (HUI $\left.{ }^{\circledR}\right)$ : concepts, measurement properties and applications. Health Qual Life Outcomes. 2003;1(1):1-13. https://doi. org/10.1186/1477-7525-1-54.

39. Weinstein MC, Torrance G, McGuire A. QALYs: the basics. Value Health. 2009;12(Suppl 1):S5-9. https://doi.org/10.1111/j. 1524-4733.2009.00515.x.

40. Whitehead SJ, Ali S. Health outcomes in economic evaluation: the QALY and utilities. Br Med Bull. 2010;96(1):5-21. https:// doi.org/10.1093/bmb/ldq033.

41. Bala MV, Mauskopf JA, Wood LL. Willingness to pay as a measure of health benefits. Pharmacoeconomics. 1999;15(1):9-18. https://doi.org/10.2165/00019053-199915010-00002.

42. Bayoumi AM. The measurement of contingent valuation for health economics. Pharmacoeconomics. 2004;22(11):691-700. https:// doi.org/10.2165/00019053-200422110-00001.

43. O'Brien B, Viramontes JL. Willingness to pay: a valid and reliable measure of health state preference? Med Decision Making. 1994;14(3):289-97. https://doi.org/10.1177/0272989X9401400 311.

44. Olsen JA, Smith RD. Theory versus practice: a review of "willingness-to-pay" in health and health care. Health Econ. 2001;10(1):39-52. https://doi.org/10.1002/1099-1050(200101) 10:1\%3c39::aid-hec563\%3e3.0.co;2-e.

45. Armstrong R, Hall BJ, Doyle J, Waters E. Cochrane Update. "Scoping the scope" of a cochrane review. J Public Health (Oxford, England). 2011;33(1):147-50. https://doi.org/10.1093/ pubmed/fdr015.

46. Colquhoun HL, Levac D, O’Brien KK, Straus S, Tricco AC, Perrier L, et al. Scoping reviews: time for clarity in definition, methods, and reporting. J Clin Epidemiol. 2014;67(12):1291-4. https:// doi.org/10.1016/j.jclinepi.2014.03.013.

47. Arksey H, O'Malley L. Scoping studies: towards a methodological framework. Int J Soc Res Methodol. 2005;8(1):19-32. https://doi. org/10.1080/1364557032000119616.

48. Happich M, Mazurek B. Priorities and prospect theory. Eur J Health Econ HEPAC Health Econ Prev Care. 2002;3(1):40-6. https://doi.org/10.1007/s10198-001-0089-y.

49. Happich M, Muehlbacher A. An exponential representation of health state utility. Eur J Health Econ HEPAC Health Econ Prev Care. 2003;4(4):292-4. https://doi.org/10.1007/ s10198-003-0186-1.

50. Happich M, von Lengerke T. Valuing the health state "tinnitus": differences between patients and the general public. Hear Res. 2005;207(1-2):50-8. https://doi.org/10.1016/j.heares.2005.04. 002.

51. Happich M, Moock J, von Lengerke T. Health state valuation methods and reference points: the case of tinnitus. Value Health. 2009;12(1):88-95. https://doi.org/10.1111/j.1524-4733.2008. 00397.x.

52. Cima RFF, Maes IH, Joore MA, Scheyen DJWM, El Refaie A, Baguley DM, et al. Specialised treatment based on cognitive behaviour therapy versus usual care for tinnitus: a randomised controlled trial. Lancet (London, England). 2012;379(9830):1951-9. https://doi.org/10.1016/S0140-6736(12)60469-3.

53. Maes IHL, Joore MA, Cima RFF, Vlaeyen JW, Anteunis LJC. Assessment of health state in patients with tinnitus: a comparison of the EQ-5D and HUI mark III. Ear Hear. 2011;32(4):428-35. https://doi.org/10.1097/AUD.0b013e3181fdf09f.

54. Maes IHL, Cima RFF, Anteunis LJC, Scheijen DJWM, Baguley DM, El Refaie A, et al. Cost-effectiveness of specialized treatment based on cognitive behavioral therapy versus usual care for tinnitus. Otol Neurotol. 2014;35(5):787-95. https://doi.org/10.1097/ MAO.0000000000000331.

55. Robinson SK, Viirre ES, Bailey KA, Gerke MA, Harris JP, Stein MB. Randomized placebo-controlled trial of a selective serotonin 
reuptake inhibitor in the treatment of nondepressed tinnitus subjects. Psychosom Med. 2005;67(6):981-8. https://doi.org/10. 1097/01.psy.0000188479.04891.74.

56. Robinson SK, Viirre ES, Bailey KA, Kindermann S, Minassian AL, Goldin PR, et al. A randomized controlled trial of cognitivebehavior therapy for tinnitus. Int Tinnitus J. 2008;14(2):119-26.

57. Stephens D, Pyykkö I, Yoshida T, Kentala E, Levo H, Auramo Y, Poe D. The consequences of tinnitus in long-standing Ménière's disease. Auris Nasus Larynx. 2012;39(5):469-74. https://doi.org/ 10.1016/j.anl.2011.10.011.

58. Summerfield AQ, Barton GR, the UK Cochlear Implant Study Group. Sensitivity of EQ-5D-3L, HUI2, HUI3, and SF-6D to changes in speech reception and tinnitus associated with cochlear implantation. Qual Life Res. 2019;28(5):1145-54. https://doi.org/ 10.1007/s11136-018-2070-6.

59. Newman CW, Sandridge SA. A comparison of benefit and economic value between two sound therapy tinnitus management options. J Am Acad Audiol. 2012;23(2):126-38. https://doi.org/ 10.3766/jaaa.23.2.7

60. Boutron I, Page MJ, Higgins JP, Altman DG, Lundh A, Hróbjartsson A. Considering bias and conflicts of interest among the included studies. In: Cochrane handbook for systematic reviews of interventions. New York: Wiley; 2019. p. 177-204. https://doi. org/10.1002/9781119536604.ch7.

61. Engineer ND, Rosellini WM, Tyler RS. Willingness to accept and pay for implantable tinnitus treatments: a survey. Neuromodul J Int Neuromodul Soc. 2013;16(2):154-62. https://doi.org/10. 1111/j.1525-1403.2012.00487.x.

62. Tyler RS. Patient preferences and willingness to pay for tinnitus treatments. J Am Acad Audiol. 2012;23(2):115-25. https://doi. org/10.3766/jaaa.23.2.6.

63. Smit JV, Pielkenrood BJ, Arts RAGJ, Janssen ML, Temel Y, Stokroos RJ. Patient acceptance of invasive treatments for tinnitus. Am J Audiol. 2018;27(2):184-96. https://doi.org/10.1044/2017_ AJA-17-0015.

64. Weinstein MC, Siegel JE, Gold MR, Kamlet MS, Russell LB. Recommendations of the panel on cost-effectiveness in health and medicine. JAMA. 1996;276(15):1253-8. https://doi.org/10.1001/ jama.1996.03540150055031.

65. Arias E. United States life tables, 2006. Natl Vital Stat Rep. 2010;58(21):1-40.

66. Drummond MF, Sculpher MJ, Torrance GW, O'Brien BJ, Stoddart GL. Methods for the economic evaluation of health care programmes. Oxford: Oxford University Press; 2005.

67. Shepard, D. S. (1999). Cost-effectiveness in Health and Medicine. By M.R. Gold, J.E Siegel, L.B. Russell, and M.C. Weinstein (eds). New York: Oxford University Press, 1996. J Mental Health Policy Econom 2(2):91-2. https://doi.org/10.1002/(SICI)1099176X(199906)2:2<91::AID-MHP46>3.0.CO;2-I

68. Meikle MB, Stewart BJ, Griest SE, Martin WH, Henry JA, Abrams HB, et al. Assessment of tinnitus: measurement of treatment outcomes. In: Langguth B, Hajak G, Kleinjung T, Cacace A, Møller AR, editors., et al., Progress in brain research, vol. 166. Amsterdam: Elsevier; 2007. p. 511-21. https://doi.org/10.1016/ S0079-6123(07)66049-X.

69. Abrams H, Chisolm TH, McArdle R. A cost-utility analysis of adult group audiologic rehabilitation: are the benefits worth the cost? J Rehabil Res Dev. 2002;39(5):549-58.

70. Ward Fuller G, Hernandez M, Pallot D, Lecky F, Stevenson M, Gabbe B. Health state preference weights for the glasgow outcome scale following traumatic brain injury: a systematic review and mapping study. Value Health. 2017;20(1):141-51. https://doi.org/ 10.1016/j.jval.2016.09.2398.

71. Yang Y, Longworth L, Brazier J. An assessment of validity and responsiveness of generic measures of health-related quality of life in hearing impairment. Qual Life Res. 2013;22(10):2813-28. https://doi.org/10.1007/s11136-013-0417-6.

72. Braun C, Rehdanz K, Schmidt U. Validity of willingness to pay measures under preference uncertainty. PLoS ONE. 2016. https:// doi.org/10.1371/journal.pone.0154078.

73. Nondahl DM, Cruickshanks KJ, Dalton DS, Klein BEK, Klein $\mathrm{R}$, Schubert CR, et al. The impact of tinnitus on quality of life in older adults. J Am Acad Audiol. 2007;18(3):257-66. https://doi. org/10.3766/jaaa.18.3.7.

74. Wilson C, Lewis P, Stephens D. The Short Form 36 (SF36) in a specialist tinnitus clinic. Int J Audiol. 2002;41(4):216-20. https:// doi.org/10.3109/14992020209078334.

75. Furlong WJ, Feeny DH, Torrance GW, Barr RD. The Health Utilities Index (HUIß) system for assessing health-related quality of life in clinical studies. Ann Med. 2001;33(5):375-84. https://doi. org/10.3109/07853890109002092.

76. Chuang L-H, Whitehead SJ. Mapping for economic evaluation. $\mathrm{Br}$ Med Bull. 2012;101(1):1-15. https://doi.org/10.1093/bmb/ldr049.

77. Longworth L, Rowen D. Mapping to obtain EQ-5D utility values for use in NICE health technology assessments. Value Health. 2013;16(1):202-10. https://doi.org/10.1016/j.jval.2012.10.010.

78. Rentz AM, Kowalski JW, Walt JG, Hays RD, Brazier JE, Yu R, et al. Development of a Preference-Based Index From the National Eye Institute Visual Function Questionnaire-25. JAMA Ophthalmol. 2014;132(3):310-8. https://doi.org/10.1001/jamaophthalmol. 2013.7639.

79. Richardson J, Iezzi A, Peacock S, Sinha K, Khan M, Misajon $\mathrm{R}$, Keeffe J. Utility weights for the vision-related assessment of quality of life (AQoL)-7D instrument. Ophthalmic Epidemiol. 2012;19(3):172-82. https://doi.org/10.3109/09286586.2012. 674613.

80. Drummond M. Introducing economic and quality of life measurements into clinical studies. Ann Med. 2001;33(5):344-9. https:// doi.org/10.3109/07853890109002088.

81. Ramsey SD, Willke RJ, Glick H, Reed SD, Augustovski F, Jonsson B, et al. Cost-effectiveness analysis alongside clinical trials II-an ISPOR good research practices task force report. Value Health. 2015;18(2):161-72. https://doi.org/10.1016/j.jval.2015. 02.001 .

82. Brazier J, Ratcliffe J, Saloman J, Tsuchiya A. Measuring and valuing health benefits for economic evaluation. Oxford: Oxford University Press; 2017.

83. Bowling A. Measuring health. London: McGraw-Hill Education; 2004.

84. Moller AR. Similarities between severe tinnitus and chronic pain. J Am Acad Audiol. 2000;11(3):115-24.

85. Folmer RL, Griest SE, Martin WH. Chronic Tinnitus as phantom auditory pain. Otolaryngol Head Neck Surg. 2001;124(4):394400. https://doi.org/10.1067/mhn.2001.114673.

86. Rauschecker JP, May ES, Maudoux A, Ploner M. Frontostriatal gating of tinnitus and chronic pain. Trends Cogn Sci. 2015;19(10):567-78. https://doi.org/10.1016/j.tics.2015.08.002.

87. Harrison JD, Young JM, Butow P, Salkeld G, Solomon MJ. Is it worth the risk? A systematic review of instruments that measure risk propensity for use in the health setting. Soc Sci Med. 2005;60(6):1385-96. https://doi.org/10.1016/j.socscimed.2004. 07.006 .

88. Martín-Fernández J, Polentinos-Castro E, del Cura-González MI, Ariza-Cardiel G, Abraira V, Gil-LaCruz AI, García-Pérez S. Willingness to pay for a quality-adjusted life year: an evaluation of attitudes towards risk and preferences. BMC Health Serv Res. 2014;14(1):287. https://doi.org/10.1186/1472-6963-14-287. 